\title{
BMJ Open Maternal post-traumatic stress disorder, depression and alcohol dependence and child behaviour outcomes in mother-child dyads infected with HIV: a longitudinal study
}

\author{
Jani Nöthling, ${ }^{1}$ Cherie L Martin, ${ }^{2}$ Barbara Laughton, ${ }^{3}$ Mark F Cotton, ${ }^{3}$ \\ Soraya Seedat ${ }^{1}$
}

To cite: Nöthling J,

Martin CL, Laughton B, et al. Maternal post-traumatic stress disorder, depression and alcohol dependence and child behaviour outcomes in mother-child dyads infected with HIV: a longitudinal study. BMJ Open 2013;3:e003638.

doi:10.1136/bmjopen-2013003638

- Prepublication history for this paper is available online. To view these files please visit the journal online (http://dx.doi.org/10.1136/ bmjopen-2013-003638).

Received 22 July 2013 Revised 11 November 2013 Accepted 14 November 2013

CrossMark

For numbered affiliations see end of article.

Correspondence to Jani Nöthling; janinothling@sun.ac.za

\section{ABSTRACT}

Objectives: HIV and psychiatric disorders are prevalent and often concurrent. Childbearing women are at an increased risk for both HIV and psychiatric disorders, specifically depression and post-traumatic stress disorder (PTSD). Poor mental health in the peripartum period has adverse effects on infant development and behaviour. Few studies have investigated the relationship between maternal PTSD and child behaviour outcomes in an HIV vertically infected sample. The aim of this study was to investigate whether maternal postpartum trauma exposure and PTSD were risk factors for child behaviour problems. In addition, maternal depression, alcohol abuse and functional disability were explored as cofactors.

Setting: The study was conducted in Cape Town, South Africa.

Participants: 70 mother-child dyads infected with HIV were selected from a group of participants recruited from community health centres.

Design: The study followed a longitudinal design. Five measures were used to assess maternal trauma exposure, PTSD, depression, alcohol abuse and functional disability at 12 months postpartum: Life Events Checklist (LEC), Harvard Trauma Scale (HTS), Alcohol Use Disorders Identification Test (AUDIT), Center for Epidemiological Studies Depression (CESD) Scale and the Sheehan Disability Scale (SDS). Child behaviour was assessed at 42 months with the Child Behaviour Checklist (CBCL).

Results: The rate of maternal disorder was high with $50 \%$ scoring above the cut-off for depression, $22.9 \%$ for PTSD and 7\% for alcohol abuse. Half of the children scored within the clinical range for problematic behaviour. Children of mothers with depression were significantly more likely to display total behaviour problems than children of mothers without depression. Maternal PTSD had the greatest explanatory power for child behaviour problems, although it did not significantly predict child outcomes. Conclusions: This study highlights the importance of identifying and managing maternal PTSD and

\section{Strengths and limitations of this study}

- This study is, to our knowledge, the first to investigate post-traumatic stress disorder as a predictor of child behaviour in vertically transmitted, mother-child dyads infected with HIV.

- The study employed a longitudinal design with the child participants being relatively healthy as indicated by immunological status.

- The sample size of the study may have reduced statistical power. Poor maternal physical health, change in child's medical treatment and change in caregiver may have biased the results.

depression in mothers of children infected with HIV. The relationship between maternal PTSD and child behaviour warrants further investigation.

\section{INTRODUCTION}

The prevalence of psychiatric disorders in the general South African population is relatively high compared with other countries, with an estimated lifetime prevalence of $30.3 \%$ and 12-month prevalence of $16.5 \% .^{1}$ Depression, alcohol abuse and post-traumatic stress disorder (PTSD) are commonly diagnosed disorders with a 12-month prevalence rate of $4.9 \%$, $4.5 \%$ and $0.7 \%$, respectively. ${ }^{1}{ }^{2}$ Among South Africans, alcohol abuse has a lifetime prevalence rate of $11.4 \%$ followed by depression at $9.8 \%$ and PTSD at 2.3\%. ${ }^{2}$ Postpartum depression is also prevalent in South Africa. High prevalence rates of $28 \%$ and $34.7 \%$ have been reported among new mothers. ${ }^{3}$

In addition to the high prevalence of psychiatric disorders, South Africa is overly burdened by HIV infection with a prevalence rate of $11 \% .{ }^{4}$ Common psychiatric disorders are often 
associated with HIV infection, ${ }^{5-8}$ with depression nearly twice as common in infected individuals. ${ }^{6}$ One study documented a $19 \%$ prevalence of common psychiatric disorders among South Africans infected with HIV, with $14 \%$ meeting criteria for depression, $5 \%$ for PTSD and $7 \%$ for alcohol dependence or abuse. ${ }^{8}$ Individuals newly diagnosed with HIV are at an even higher risk for a common psychiatric disorder. ${ }^{7}$ In addition, women are disproportionately and dually burdened by HIV and mood and anxiety disorders. Female gender is considered a risk factor for mood and anxiety disorders and for increased severity of these disorders. ${ }^{1}$ Women, especially childbearing women, are disproportionally affected by HIV. ${ }^{3}$

Poor maternal mental health is associated with adverse long-term effects in child development and behaviour. ${ }^{9-14}$ Prevalence rates of $16 \%-30 \%$ and $7 \%-31 \%$ for externalising behaviour problems and internalising behaviour problems, respectively, have been identified among preschool children in low-income families. ${ }^{15}$ Internalising and externalising behaviour problems can persist into adolescence. For example, infant negative emotional reactivity and shyness have been associated with inhibition and withdrawal in early childhood and with anxiety symptoms in middle childhood and adolescence. ${ }^{16}$ Negative reactivity, low persistence, aggression and school difficulties in childhood have also been associated with substance abuse in adolescence. ${ }^{17}$

Maternal depression, including postpartum depression, is linked to various forms of child and infant internalising and externalising behaviour problems, such as insecure attachment and less optimal mother-child interaction $^{310}{ }^{13}$; higher levels of tension and lower levels of emotional development ${ }^{9}$; low social competence and adaptive functioning ${ }^{11}$; poorer cognitive development ${ }^{9}$; lower competencies and general behaviour problems in boys ${ }^{10}$; and attention-deficit hyperactivity disorder. ${ }^{13}$

Furthermore, children of mothers with comorbid PTSD and depression are significantly more likely to display internalising and externalising behaviour problems compared with children of mothers with depression only. ${ }^{14}$ These children are more likely to display somatic symptoms and are more likely to be emotionally reactive, anxious/depressed and aggressive. ${ }^{14}$ South Africa has a high rate of exposure to violence and traumatic events which increases risk for PTSD. ${ }^{18}$ Prevalence of PTSD and trauma exposure is high among individuals infected with HIV, with female gender being a significant risk factor in this group..$^{5-8} 1920$ Women infected with HIV are therefore at high risk of PTSD and their children are consequently at risk of behavioural and developmental problems.

Maternal stress and anxiety is also linked to child behaviour problems. Various studies have investigated the negative effects of antenatal maternal stress on child development. ${ }^{21}$ Fewer studies have focused on postpartum maternal stress and anxiety and child behaviour outcomes. However, maternal stress and anxiety is negatively associated with parenting skills, and with infant and child behaviour problems. ${ }^{22-24}$ Maternal anxiety is a significant predictor of child attention and aggression problems ${ }^{25}$ and maternal stress is significantly associated with anxiety and depressive symptoms in the child. ${ }^{26}$

In addition to anxiety, PTSD and depression, maternal postpartum alcohol abuse/dependence has been associated with child and infant behaviour problems and developmental risk. ${ }^{27-30}$ Alcohol abuse is one of the major contributors to disease burden in South Africa and antenatal alcohol abuse is associated with high rates of fetal alcohol spectrum disorders. ${ }^{31-35}$ Child behaviour problems associated with parental postpartum alcohol abuse/dependence include poor inhibitory control, attention shifting, distractibility, defiance, aggression, delinquency, emotional reactivity and withdrawal. ${ }^{28} 36$

To date, few studies have investigated the relationship between maternal postpartum trauma exposure, PTSD and child behaviour outcomes. None, to our knowledge, have examined this relationship in individuals infected with HIV, despite evidence of high prevalence of PTSD in this group and its public health implications. This is of significant public health concern particularly in the South African context. The primary aim of this study was to investigate the impact of maternal trauma exposure and PTSD at a specific time point (12 months postpartum) and their association with child behaviour (at 3.5 years of age) in mother-child dyads, infected with HIV, while controlling for the effects of depression. The secondary aim of the study was to investigate the relationship between maternal alcohol dependence/abuse, functional disability and child behaviour outcomes.

\section{METHODS}

\section{Participants}

Seventy mother-child dyads infected with HIV participated in this study. Data were collected between 2006 and 2010. In eight cases, the maternal caregiver was not the child's biological mother. 'Maternal' or 'mother' within the context of this study therefore refers to either the biological mother or primary caregiver of the child. The child had to be in the care of the caregiver for at least 6 months prior to the assessments to qualify as a suitable participant. The mother-child dyads were selected, based on the completeness of their data, as a subgroup from the Children with HIV Early Antiretroviral Therapy (CHER) trial. Infants infected with HIV entered the CHER trial at a mean of 7 weeks of age and were randomised to early antiretroviral therapy for either 40 or 96 weeks followed by planned treatment interruption or deferred therapy until meeting treatment guideline thresholds at that time; a CD4 below 20\% (25\% in first year of life) or progression of HIV disease. The CHER study started in 2005 and ended in 2011. ${ }^{37}$ The study was conducted in two South African sites, the Perinatal HIV Research Unit in Soweto and the Children's Infectious Diseases Clinical Research Unit (KID-CRU) in Tygerberg Children's Hospital, Cape Town. Participants were identified and recruited from local community health centres through HIV vertical 
transmission prevention programmes. A neurodevelopmental substudy was conducted in KID-CRU, and the data collected at this site were used in the current study.

\section{Study design}

The neurodevelopmental substudy reported herein was conducted over 5 years, and included all infants with birth weight $>2000 \mathrm{~g}$ and normal neurological examination before 12 weeks of age and excluded infants with central nervous system (CNS) insults other than due to HIV. Maternal assessments were completed at 10-12 months and infant assessments at 42 months of age. The ethics committee granted a waiver of parental consent for participants who were less than 18 years of age.

\section{Procedures}

Informed consent was obtained from all mothers of infants (aged 16 years and older) infected with HIV, in their preferred language (English, Afrikaans or isiXhosa). Maternal participants completed a series of questionnaires including a demographic questionnaire, the Life Events Checklist (LEC), the Harvard Trauma Scale (HTS), the Alcohol Use Disorder Identification Test (AUDIT), the Center for Epidemiologic Studies Depression (CESD) Scale and the Sheehan Disability Scale (SDS). The same battery of questionnaires was completed at five different time points over the course of 5 years. The assessments completed at 12 months postpartum were used in the current analysis. This was deemed a salient period for examining PTSD in new mothers and was intended to decrease the risk of confounding by postpartum depression, as the risk for postpartum depression is highest within the first year after giving birth. The self-report measures were verbally administered in Afrikaans and English by a trained research psychologist. A trained research assistant was used for Xhosa-speaking mothers.

Child behaviour was assessed at 42 months postpartum using the Child Behaviour Checklist (CBCL). This time point was selected based on completeness of data and in an effort to measure the long-term effects of maternal mental health. The mother or caregiver of the child completed the CBCL. The CBCL was administered by a research assistant if the mothers were illiterate or had difficulty completing the assessment. Immunodeficiency in children was measured using $\mathrm{CD} 4$ percentages and absolute scores. Immunodeficiency was determined according to the WHO's guidelines on the classification of HIV-associated immunodeficiency in children. ${ }^{38}$ The CD4 counts and percentages of children were determined on a regular basis, but viral loads were only determined if there were concerns about treatment failure. Maternal CD4 counts and viral loads were not assessed as mothers were not receiving treatment at the same facility as the children.

\section{Measures}

Demographic questionnaire

Biographical information regarding maternal age, ethnicity, language, marital status, education, annual household income, employment status and gender of the child was determined through a demographic questionnaire. The relationship of the caregiver with the child was also obtained.

\section{Life Events Checklist}

Traumatic life events (LEs) were measured using the LEC. The LEC is a 16-item self-report questionnaire assessing the incidence of 16 different categories of traumatic events including physical assault, life-threatening illness, natural disasters, sexual assault and sudden unexpected death of a loved one. Participants had three optional responses to each item; direct 'happened to me', indirect 'witnessed it' and removed 'heard about it'. A score was then tallied for the total number of direct LEs. Respondents who reported directly experienced trauma were asked to complete the HTS.

\section{Harvard Trauma Scale}

The HTS is a 30-item, self-report questionnaire designed to screen for the presence of PTSD in cross-cultural populations. ${ }^{39}$ Examples of items include 'feeling as though the event is happening again' and 'nightmares about the event that keep coming back'. Symptoms are reported on a 4-point Likert scale ranging from 'not at all' to 'extremely', with a total score range of 30-120. The cut-off score indicative of PTSD is 75 or higher. The HTS has shown strong test-retest reliability in a South African, adolescent sample. ${ }^{40}$

\section{Alcohol Use Disorders Identification Test}

Alcohol dependence and abuse were measured using the AUDIT. The 10-item questionnaire assesses alcohol dependence and abuse and is scored on a 5-point Likert scale from 'never' to 'daily or almost daily'. The cut-off score is set at eight for alcohol abuse and 13 or more for alcohol dependence. The AUDIT is a reliable measure developed by the WHO and has been implemented and tested internationally. ${ }^{41}$ It has been applied in a variety of settings and cultures ${ }^{42-44}$ including Mexico, ${ }^{45}$ Venezuela, ${ }^{46}$ Hong Kong, ${ }^{47}$ Zimbabwe $^{48}$ and in South Africa with patients infected with HIV. ${ }^{49}{ }^{50}$ In each of these studies, the AUDIT outperformed other self-report measures in the identification of alcohol abuse and dependence.

\section{Center for Epidemiological Studies Depression Scale}

The CESD Scale is a self-report measure to screen for depression. The CESD Scale is a 20-item scale that assesses current levels of depression as per the Diagnostic and Statistical Manual of Mental Disorders, 4th Edition (DSM-IV) criteria. Responses are measured on a 4-point Likert scale ranging from 'rarely or none of the time' to 'most or all of the time'. A score of 16 or more is considered indicative of depression. The CESD Scale has been validated for clinic and community settings to detect depressive symptoms ${ }^{51-53}$ and in many cross-cultural samples $^{54-56}$ and across ethnic groups. ${ }^{57}$ The CESD 
Scale has been used to measure depression in several clinic samples of individuals infected with HIV. ${ }^{59-62}$

\section{Sheehan Disability Scale}

SDS is a self-report measure used to evaluate patients' functional impairment in relation to self-reported symptoms. ${ }^{63}$ Functional disability is assessed across three core areas, namely, work/school, social life and at home/family responsibilities. Functioning is reported on a visual analogue scale ranging from 0 to 10 . Higher scores indicate greater impairment and disability. The SDS is frequently used in clinical trials in psychiatry and has shown good reliability in a South African sample infected with HIV. ${ }^{64}$

\section{Child Behaviour Checklist}

Child behaviour problems were assessed using the preschool version of the CBCL. ${ }^{65}$ CBCL is a 100 -item self-report questionnaire, usually completed by a parent or caregiver. The items are scored on a 3-point Likert scale ranging from 'not true' to 'very true or often true'. Behavioural problems are measured in eight domains, namely, emotionally reactive, anxious/depressed, somatic symptoms, withdrawn behaviour, sleep problems, common/non-specific problems, attention problems and aggressive behaviour. The first four domains are viewed as internalising behaviour problems, the last two domains are viewed as externalising behaviour problems and all of the domains combined are viewed as total behaviour problems. The CBCL is a widely used behavioural checklist with good reliability and validity in a variety of cultural and language settings. ${ }^{66-68}$

\section{Data analysis}

All analyses were performed using Statistical Analysis Software (SAS) and SPSS V.20. Descriptive statistics were computed for the demographic characteristics of the sample as well as the prevalence rates of maternal mental health problems and child behavioural problems. The differences in behaviour problems between children of mothers with and without PTSD, depression and alcohol abuse were analysed by means of $t$ tests. Linear regression analysis was performed to determine whether maternal mental status was a significant predictor of child behaviour outcomes. Of particular interest was the influence of trauma exposure and PTSD on child behaviour outcomes. Depression was controlled for due to previous studies reporting a relationship between depression and child behaviour problems.

Three models were run with the following continuous outcome variables as measured by the CBCL: total child behavioural problems (internalising, externalising and sleep problems), child internalising behaviour problems and child externalising behaviour problems. The same continuous predictor variables were used in all three regression models. The predictor variables were exposure to traumatic LEs, PTSD symptomatology (HTS), alcohol abuse/dependence (AUDIT), depression (CESD Scale) and functional disability (SDS).

\section{RESULTS}

\section{Sample demographics}

The sample included 70 mother-child dyads, each being HIV infected. The mean age of the mothers/caregivers at 12 months postpartum was 28.8 (range 16-64) years. The mother-child dyads were mainly black $(88.6 \%)$ and Xhosa speaking $(65.7 \%)$. The mothers were mostly single $(64.3 \%)$ and unemployed $(80.9 \%)$. The majority of mothers had some secondary schooling $(58.6 \%)$ with an annual income below R10000 (US\$1038, 72.9\%). Thirty-six children $(51 \%)$ were female. The majority of caregivers at 10-12 months (94.3\%) and 42 months $(91.4 \%)$ were the biological mothers of the children; however, there were eight changes in caregivers from 12 months postpartum to 42 months postpartum. Reasons for change in caregiver included mother passed away $(n=3)$, mother was unavailable on the day of assessment $(n=2)$ and the person attending lived with the child and was closely involved in caring for the child $(n=3)$.

The prevalence of infant immunodeficiency was relatively high at 10-12 months postpartum with $47.1 \%$ (range 15.4-54.5\%) and 40\% (range 574-3777), showing mild-to-severe immunodeficiency based on CD4 percentages and absolute counts, respectively. At 42 months, the majority of the children did not have CD4 percentages (91.4\%, range $16.3-53.6 \%)$ or absolute counts $(100 \%$, range 468-3267) indicative of immunodeficiency. The demographic and biological information of participants are presented in table 1 .

\section{Prevalence of maternal psychiatric disorders and child behaviour problems}

The prevalence rate for all measured maternal psychiatric disorders (based on self-report data) was $27.6 \%$. Depression was the most prevalent disorder at $50 \%$ $(\mathrm{n}=35)$, followed by PTSD at $22.9 \% \quad(\mathrm{n}=16)$, alcohol abuse at $7.1 \% \quad(\mathrm{n}=5)$ and alcohol dependence at $2.9 \%$ $(n=2)$. A large proportion of children scored within the clinical range for problematic behaviour with a prevalence rate of $44.3 \% \quad(n=31)$ for total behaviour problems. Internalising behaviour problems were most prevalent with $50 \%$ of children scoring above the cut-off. The most common internalising behaviour problems were somatic symptoms $(n=28)$, followed by withdrawn behaviour $(\mathrm{n}=20)$, emotional reactivity $(\mathrm{n}=15)$ and anxious/ depressed behaviour $(n=10)$. Externalising behavioural problems were less prevalent with $30 \% \quad(n=21)$ of children scoring within the clinical range. Aggressive behaviour $(n=12)$ was the most common externalising behaviour problem followed by attention problems $(n=8)$. Sleeping problem $(n=3)$ was the least common behaviour problem (see table 2).

\section{Maternal mental health as a predictor of child behaviour outcomes}

The children of mothers with depression $(M=53.74$, $\mathrm{SE}=28.53)$ were significantly more likely to display behaviour problems t $(68)=2.15, p=0.035$, compared with the 
Table 1 Demographic layout of the sample

\begin{tabular}{|c|c|c|c|}
\hline & $\mathbf{N}$ & Per cent & $\mathbf{M}$ \\
\hline $\begin{array}{l}\text { Relationship of carer with child at } \\
12 \text { months postpartum* }\end{array}$ & 70 & & \\
\hline Mother & 66 & 94.3 & \\
\hline Grandmother & 2 & 2.9 & \\
\hline Aunt & 1 & 1.4 & \\
\hline Guardian & 1 & 1.4 & \\
\hline $\begin{array}{l}\text { Relationship of carer with child at } \\
42 \text { months postpartum } t\end{array}$ & 70 & & \\
\hline Mother & 64 & 91.4 & \\
\hline Grandmother & 5 & 7.1 & \\
\hline Aunt & 1 & 1.4 & \\
\hline Age of mother/caregiver* & 70 & & 28.8 \\
\hline Gender of child* & 70 & & \\
\hline Male & 34 & 48.6 & \\
\hline Female & 36 & 51.4 & \\
\hline Language* & 70 & & \\
\hline Afrikaans & 9 & 12.9 & \\
\hline English & 15 & 21.4 & \\
\hline Xhosa & 46 & 65.7 & \\
\hline Ethnicity* & 70 & & \\
\hline Black & 62 & 88.6 & \\
\hline Coloured & 3 & 4.3 & \\
\hline White & 4 & 5.7 & \\
\hline Asian & 1 & 1.4 & \\
\hline Marital status* & 70 & & \\
\hline Single & 45 & 64.3 & \\
\hline Married/living with a partner & 23 & 32.9 & \\
\hline Divorced/separated & 2 & 2.9 & \\
\hline Annual income* & 70 & & \\
\hline$<\mathrm{R} 10000$ & 51 & 72.9 & \\
\hline R10 000-R20 000 & 11 & 15.7 & \\
\hline R20 000-R40 000 & 2 & 2.9 & \\
\hline R40 000-R60 000 & 0 & 0 & \\
\hline R60 000-R100 000 & 1 & 1.4 & \\
\hline$>\mathrm{R} 100000$ & 0 & 0 & \\
\hline Level of education* & 70 & & \\
\hline No schooling & 0 & 0 & \\
\hline Some primary schooling & 7 & 10 & \\
\hline Completed primary school & 3 & 4.3 & \\
\hline Some secondary schooling & 41 & 58.6 & \\
\hline Grade 12 completed & 18 & 25.7 & \\
\hline Higher education completed & 1 & 1.4 & \\
\hline Employment status* & 68 & & \\
\hline Employed & 13 & 19.1 & \\
\hline Unemployed & 55 & 80.9 & \\
\hline $\begin{array}{l}\text { Immunodeficiency (CD4 } \\
\text { percentage) of child* }\end{array}$ & 70 & & 36.1 \\
\hline Not significant (>30\%) & 37 & 52.9 & \\
\hline Mild (25-30\%) & 15 & 21.4 & \\
\hline Advanced (20-24\%) & 12 & 17.1 & \\
\hline Severe $(<20 \%)$ & 6 & 8.6 & \\
\hline $\begin{array}{l}\text { Immunodeficiency (CD4 absolute } \\
\text { score) of child* }\end{array}$ & 70 & & 1862.6 \\
\hline Not significant & 42 & 60 & \\
\hline Significant $(<750)$ & 28 & 40 & \\
\hline $\begin{array}{l}\text { Immunodeficiency (CD4 } \\
\text { percentage) of child } †\end{array}$ & & & 34.3 \\
\hline Not significant $(>25 \%)$ & 64 & 91.4 & \\
\hline
\end{tabular}

Table 1 Continued

\begin{tabular}{lrll}
\hline & N & Per cent & M \\
\hline Mild (20-25\%) & 4 & 5.7 & \\
Advanced (15-19\%) & 2 & 2.9 & \\
Severe (<15\%) & 0 & 0 & \\
Immunodeficiency (CD4 absolute & & & 1374.2 \\
count) of child $†$ & & & \\
Not significant & 70 & 100 & \\
Significant $(<350)$ & 0 & 0 & \\
\hline
\end{tabular}

*Data recorded at 12 months postpartum.

†Data recorded at 42 months postpartum.

children of mothers without depression ( $\mathrm{M}=39.09$, $\mathrm{SE}=28.59)$. The children of mothers meeting criteria for PTSD $(\mathrm{M}=54.06, \mathrm{SE}=18.97)$ were more likely to display behaviour problems compared with the children of mothers who did not meet criteria for PTSD (M=44.25, $\mathrm{SE}=30.76)$, but this was not a significant effect $\mathrm{t}(58)$ $=1.19, \mathrm{p}=0.238$. The children of mothers who abused alcohol $(\mathrm{M}=52.60, \mathrm{SE}=24.52)$ were also more likely to display behaviour problems, compared with the children of mothers who did not abuse alcohol $(\mathrm{M}=45.94$, $\mathrm{SE}=29.74)$, but this effect was also not significant $\mathrm{t}(68)$ $=0.49, \mathrm{p}=0.628$ (see table 3 ).

Table 4 presents the results of the regression analyses with predictor variables, their standardised coefficients and significance levels for the outcome variables: child total behaviour problems (model 1), child internalising behaviour problems (model 2) and child externalising behaviour problems (model 3). Table 5 presents the summary statistics for the regression analysis.

The linear combination of maternal variables, namely, traumatic LEs, PTSD, depression, alcohol dependence/ abuse and functional disability explained $3.63 \%$ of the variance in total child behaviour problems in model 1 . The amount of variance explained was not significant $\mathrm{F}$ $(5,53)=1.44, p=0.226$. None of the predictor variables significantly contributed in predicting child behaviour problems within this model. Maternal PTSD $\beta=0.35$, $\mathrm{t}(59)=1.38 ; \mathrm{p}=0.173$ made the largest contribution to explaining total child behaviour problems, based on standardised $\beta$ coefficients and significance levels, followed by traumatic LEs $\beta=-1.79$, t $(59)=-0.94 ; \mathrm{p}=0.352$, depression $\beta=0.20$, t $(59)=0.61 ; p=0.546$, disability in functioning $\beta=0.24, \mathrm{t} \quad(59)=0.40 ; \mathrm{p}=0.688$ and alcohol dependence /abuse $\beta=-0.14$, t (59) $=-0.13 ; \mathrm{p}=0.894$.

The linear combination of the maternal variables in model 2 explained $7.02 \%$ of the variance in child internalising behaviour problems. The amount of variance explained in this model was also not significant $\mathrm{F}(5,53)$ $=1.44, p=0.226$. None of the predictor variables significantly contributed to predicting child internalising behaviour problems. Maternal PTSD $\beta=0.12$, t $(59)=1.29 ; \mathrm{p}=0.203$ made the largest contribution to explaining child internalising behaviour problems, based on standardised $\beta$ coefficients, followed by traumatic LEs $\beta=-1.18$, t (59)=-1.64; 
Table 2 Descriptive statistics for maternal mental health and child behaviour problems

\begin{tabular}{|c|c|c|c|c|}
\hline & \multirow[b]{2}{*}{$\mathbf{M}$} & \multirow[b]{2}{*}{ SD } & \multicolumn{2}{|c|}{ Above cut-off } \\
\hline & & & $\overline{\mathbf{N}}$ & Per cent \\
\hline Directly experienced LEs* & 2.36 & 2.13 & & \\
\hline Substance abuse (AUDIT)* & 1.30 & 3.45 & & \\
\hline Hazardous drinking & & & 5 & 7.1 \\
\hline Alcohol dependence & & & 2 & 2.9 \\
\hline Depression (CESD)* & 17.40 & 14.05 & 35 & 50 \\
\hline Post-traumatic stress disorder (HTS)* & 59.67 & 21.36 & 16 & 22.9 \\
\hline Functional disability (SDS)* & 7.11 & 6.75 & & \\
\hline Total behaviour problems (CBCL)†, $\ddagger$ & 46.41 & 29.30 & 31 & 44.3 \\
\hline Sleep & 3.16 & 2.67 & 3 & 4.3 \\
\hline Internalising behaviour problems (CBCL) $†$ & 14.67 & 11.07 & 35 & 50.0 \\
\hline Emotional reactive & 3.20 & 3.39 & 15 & 21.4 \\
\hline Anxious/depressed & 3.73 & 2.85 & 10 & 14.3 \\
\hline Somatic & 4.61 & 3.57 & 28 & 40.0 \\
\hline Withdrawn & 3.13 & 3.02 & 20 & 28.6 \\
\hline Externalising behaviour problems (CBCL)† & 14.59 & 9.07 & 21 & 30.0 \\
\hline Attention & 2.74 & 1.97 & 8 & 11.4 \\
\hline Aggression & 11.84 & 7.77 & 12 & 17.1 \\
\hline \multicolumn{5}{|c|}{$\begin{array}{l}\text { *Maternal measures. } \\
\text { †Child measures. } \\
\text { †Total behaviour problems comprise internalising behaviour problems, externalising behaviour problems and sleeping problems. } \\
\text { AUDIT, Alcohol Use Disorders Identification Test; CBCL, Child Behaviour Checklist; CESD, Center for Epidemiological Studies Depression } \\
\text { Scale; HTS, Harvard Trauma Scale; LEs, life events; SDS, Sheehan Disability Scale. }\end{array}$} \\
\hline
\end{tabular}

$\mathrm{p}=0.106$, depression $\beta=0.14$, $\mathrm{t}(59)=1.12 ; \mathrm{p}=0.268$, alcohol dependence/abuse $\beta=-0.39$, t $(59)=-0.99 ; \mathrm{p}=0.328$ and functional disability $\beta=0.06$, t $(59)=0.28 ; \mathrm{p}=0.781$.

Maternal variables explained $6.66 \%$ of the variance in child externalising behaviour problems in model 3 and the variance explained was once again not significant $\mathrm{F}$ $(5,53)=1.83, \mathrm{p}=0.123$. None of the predictor variables significantly contributed to explaining child externalising behaviour problems. Maternal PTSD $\beta=0.14, \mathrm{t}$ (59) $=1.79 ; \mathrm{p}=0.079$ made the largest contribution, based on standardised $\beta$ coefficients and significance levels, followed by alcohol dependence/abuse $\beta=0.37$, t (59) $=1.12 ; \mathrm{p}=0.270$, traumatic LEs $\beta=-0.15$, t $(59)=-0.25$; $\mathrm{p}=0.807$, depression $\beta=0.01$, $\mathrm{t}(59)=0.11 ; \mathrm{p}=0.909$ and functional disability $\beta=0.02, \mathrm{t}(59)=0.08 ; \mathrm{p}=0.936$.

\section{DISCUSSION}

The present study examined the long-term effects of maternal mental health and child behaviour outcomes in a sample of mother-child dyads infected with HIV. First, we found that maternal mental disorders and child behaviour problems were common among mothers infected with HIV and vertically infected children. The overall prevalence of maternal psychiatric disorders, based on self-report data, was 27.6\%. Previous studies have reported prevalence rates of $19-56 \%$ among samples infected with HIV. ${ }^{5-8}$ Half of the mothers in this study scored above the cut-off for depression, followed by $22.9 \%$ for PTSD, $7.1 \%$ for alcohol abuse and $2.9 \%$ for alcohol dependence. Similarly, previous studies have reported high prevalence rates, among samples infected

Table 3 Comparison of CBCL scores for child behaviour problems based on maternal mental status

\begin{tabular}{|c|c|c|c|c|c|}
\hline & $\mathbf{M}$ & SD & Df & t test & p Value \\
\hline Maternal depression (CESD) & & & 68 & 2.15 & 0.035 \\
\hline Children of mothers with depression & 53.74 & 28.53 & & & \\
\hline Children of mothers without depression & 39.09 & 28.59 & & & \\
\hline Maternal PTSD (HTS) & & & 58 & 1.19 & 0.238 \\
\hline Children of mothers with PTSD & 54.06 & 18.97 & & & \\
\hline Children of mothers without PTSD & 44.25 & 30.76 & & & \\
\hline Maternal alcohol abuse (AUDIT) & & & 68 & 0.49 & 0.628 \\
\hline Children of mothers who abuse alcohol & 52.60 & 24.52 & & & \\
\hline Children of mothers who do not abuse alcohol & 45.94 & 29.74 & & & \\
\hline
\end{tabular}

1. Outcome: total child behaviour problems (CBCL).

2. Outcome: internalising child behaviour problems $(\mathrm{CBCL})$.

3. Outcome: externalising child behaviour problems (CBCL).

AUDIT, Alcohol Use Disorders Identification Test; CBCL, Child Behaviour Checklist; CESD, Center for Epidemiological Studies Depression Scale; HTS, Harvard Trauma Scale; PTSD, post-traumatic stress disorder. 
Table 4 Parameters for the variables predicting child behaviour outcomes $(\mathrm{N}=59)$

\begin{tabular}{|c|c|c|c|c|c|c|c|c|}
\hline \multirow[b]{2}{*}{ Model } & & \multicolumn{2}{|c|}{ Unstandardised } & \multirow[b]{2}{*}{$\begin{array}{l}\text { Standardised } \\
\beta \text { coefficients }\end{array}$} & \multirow[b]{2}{*}{ t test } & \multirow[b]{2}{*}{ Significance } & \multicolumn{2}{|l|}{$95 \% \mathrm{C}$} \\
\hline & & $\boldsymbol{\beta}$ & SE & & & & $\begin{array}{l}\text { Lower } \\
\text { limit }\end{array}$ & $\begin{array}{l}\text { Upper } \\
\text { limit }\end{array}$ \\
\hline \multirow[t]{6}{*}{1} & Total problems (constant) & 26.02 & 11.49 & & 2.27 & 0.028 & 4.33 & 47.71 \\
\hline & Traumatic LEs & -1.79 & 1.91 & -0.13 & -0.94 & 0.352 & -5.40 & 1.81 \\
\hline & $\begin{array}{l}\text { Alcohol dependance/abuse } \\
\text { (AUDIT) }\end{array}$ & -0.14 & 1.07 & -0.02 & -0.13 & 0.894 & -2.16 & 1.87 \\
\hline & Depression (CESD) & 0.20 & 0.33 & 0.10 & 0.61 & 0.546 & -0.42 & 0.82 \\
\hline & Functional disability (SDS) & 0.24 & 0.60 & 0.06 & 0.40 & 0.688 & -0.89 & 1.38 \\
\hline & PTSD (HTS) & 0.35 & 0.26 & 0.27 & 1.38 & 0.173 & -0.13 & 0.83 \\
\hline \multirow[t]{6}{*}{2} & Internalising problems (constant) & 8.14 & 4.30 & & 1.89 & 0.064 & 0.02 & 16.27 \\
\hline & Traumatic LEs & -1.18 & 0.72 & -0.23 & -1.64 & 0.106 & -2.53 & 0.18 \\
\hline & $\begin{array}{l}\text { Alcohol dependance/abuse } \\
\text { (AUDIT) }\end{array}$ & -0.39 & 0.40 & -0.13 & -0.99 & 0.328 & -1.15 & 0.36 \\
\hline & Depression (CESD) & 0.14 & 0.12 & 0.19 & 1.12 & 0.268 & -0.09 & 0.37 \\
\hline & Functional disability (SDS) & 0.06 & 0.22 & 0.04 & 0.28 & 0.781 & -0.36 & 0.49 \\
\hline & PTSD (HTS) & 0.12 & 0.10 & 0.24 & 1.29 & 0.203 & -0.06 & 0.30 \\
\hline \multirow[t]{6}{*}{3} & Externalising problems (constant) & 6.05 & 3.62 & & 1.67 & 0.100 & -0.78 & 12.88 \\
\hline & Traumatic LEs & -0.15 & 0.60 & -0.03 & -0.25 & 0.807 & -1.28 & 0.99 \\
\hline & $\begin{array}{l}\text { Alcohol dependance/abuse } \\
\text { (AUDIT) }\end{array}$ & 0.37 & 0.34 & 0.15 & 1.12 & 0.270 & -0.26 & 1.01 \\
\hline & Depression (CESD) & 0.01 & 0.10 & 0.02 & 0.11 & 0.909 & -0.18 & 0.21 \\
\hline & Functional disability (SDS) & 0.02 & 0.19 & 0.01 & 0.08 & 0.936 & -0.34 & 0.37 \\
\hline & PTSD (HTS) & 0.14 & 0.08 & 0.34 & 1.79 & 0.079 & -0.01 & 0.30 \\
\hline
\end{tabular}

AUDIT, Alcohol Use Disorders Identification Test; CESD, Center for Epidemiological Studies Depression Scale; HTS, Harvard Trauma Scale; LEs, life events; PTSD, post-traumatic stress disorder; SDS, Sheehan Disability Scale.

with HIV, for depression (14-36\%), PTSD (5-14.8\%) and alcohol dependence $(7 \%) .^{5-8}$ The results of this study revealed even higher prevalence rates for depression and PTSD and lower prevalence rates for alcohol dependence.

The prevalence of psychiatric disorder was also considerably higher than rates documented in the general South African population. ${ }^{1}$ Previous studies have found

Table 5 Model summary predicting child behaviour problems

\begin{tabular}{lllllll}
\hline Model & $\mathbf{R}^{\mathbf{2}}$ & $\boldsymbol{\Delta} \mathbf{R}^{\mathbf{2}}$ & $\mathbf{F}$ & $\mathbf{d f 1}$ & $\mathbf{d f 2}$ & $\mathbf{p ~ V a l u e}$ \\
\hline 1 & 0.119 & 0.036 & 1.44 & 5 & 53 & 0.227 \\
2 & 0.150 & 0.070 & 1.88 & 5 & 53 & 0.114 \\
3 & 0.147 & 0.067 & 1.83 & 5 & 53 & 0.123 \\
\hline
\end{tabular}

1. Predictors: maternal traumatic LEs, maternal alcohol dependence/abuse (AUDIT), maternal depression (CESD), maternal functional disability (SDS), maternal PTSD (HTS). Outcome: total child behaviour problems (CBCL).

2. Predictors: maternal traumatic LEs, maternal alcohol dependence/abuse (AUDIT), maternal depression (CESD), maternal functional disability (SDS), maternal PTSD (HTS). Outcome: internalising child behaviour problems (CBCL).

3. Predictors: maternal traumatic LEs, maternal alcohol dependence/abuse (AUDIT), maternal depression (CESD), maternal functional disability (SDS), maternal PTSD (HTS) Outcome: externalising child behaviour problems (CBCL). AUDIT, Alcohol Use Disorders Identification Test; CBCL, Child Behaviour Checklist; CESD, Center for Epidemiological Studies Depression Scale; HTS, Harvard Trauma Scale; LEs, life events; PTSD, post-traumatic stress disorder; SDS, Sheehan Disability Scale. a high prevalence (28-34.7\%) for postpartum depression in low-income populations in South Africa. We found a higher prevalence rate of $50 \%$ among this sample for depression. The added emotional and physical load of HIV infection and caring for a child infected with HIV seems to contribute considerably to psychiatric disease burden. The high prevalence rate of psychiatric disorder, especially PTSD, could possibly be biased by female gender, a previously identified risk factor for PTSD in individuals infected with HIV. ${ }^{19}$ The low rate of alcohol dependence might be due to the use of prenatal alcohol exposure as an exclusion criterion for participation in the study.

A high rate of child behaviour problems $(44.3 \%$ for total behaviour problems) was also found. The prevalence rate for internalising and externalising behaviour problems, which fell within the clinical range, was 50\% and $30 \%$, respectively. The prevalence rate of externalising behaviour problems is considerably higher than previously reported rates of $16-30 \%$. The prevalence rate for internalising behaviour problems corresponds with those identified in previous studies $(7-31 \%)$. The children in this sample are therefore at greater risk of displaying externalising behaviour problems and consequently psychiatric disorders associated with externalising behaviour problems later in life. ${ }^{1516}$

Second, children of mothers with depression were significantly more likely to exhibit behaviour problems than the children of mothers without depression, although this association was not significant for maternal 
PTSD or alcohol abuse/dependence. Various studies have found significant links between maternal depression and internalising and externalising child behaviour problems. ${ }^{3}{ }^{9-11} 13$ Fatigue and emotional burnout associated with depression may lead to poor mother-child interaction in early infancy and consequently to insecure infant attachment and behavioural problems. ${ }^{3} 69$ The added burden of caring for an ill child, guilt associated with transmission of HIV to the child and stressors associated with living in poverty may further intensify depressive symptoms. ${ }^{70}{ }^{71}$ The relationship between maternal depression and child behaviour problems was investigated in this study in an effort to control for the probable shared variance between depression and PTSD. Depression was not a significant predictor within the regression models of total behaviour problems, internalising or externalising behaviour problems.

Third, maternal trauma exposure, PTSD, depression, alcohol abuse/dependence and functional disability did not significantly predict child behaviour outcomes. However, PTSD made the largest contribution in predicting internalising, externalising and total behaviour problems. This relationship between PTSD and child behaviour problems warrants further investigation. Similar results have been reported in other studies; a significant association has been found between maternal stress and anxiety and child internalising and externalising problems. ${ }^{25} 26$ The children of mothers with comorbid PTSD and depression also have an increased risk for internalising and externalising behaviour problems, compared with mothers with depression alone or no disorder. ${ }^{14}$ Similar to depression, maternal PTSD may lead to poor mother-child interaction. Parental anxiety is associated with an overinvolved parenting style and negative parental attitudes during interaction with children. ${ }^{72}$ Children may model parent's anxious behaviour; parental vigilance, intrusion and discouragement of independent problems solving may lead to a limited sense of competence and autonomy in the children which, in turn, can lead to anxiety within the child. ${ }^{73}$ Maternal antenatal anxiety may have adverse consequences on child neurodevelopment and subsequent behavioural and emotional problems. ${ }^{74}$ While previous studies have found significant associations between parental (specifically maternal) alcohol abuse and child developmental and behaviour problems, ${ }^{36}{ }^{75}$ in the present study no significant relationship was found between alcohol dependence/abuse, functional disability and child behavioural outcomes in regression analyses.

A number of study limitations deserve mention. In eight cases, there was a change in the caregiver completing the maternal assessment at 12 months compared with the caregiver completing the child assessment at 42 months. The change in caregiver may have, in itself, contributed to behaviour problems. Caregivers may have had a limited sense of the child's temperament (owing to the short period of caring for the child), leading to inaccurate representation of the child's behaviour. Several confounding factors, apart from maternal mental health, may have influenced child behaviour problems. Maternal physical health, child physical health, change in child's medication (assigned treatment arm), socioeconomic stressors and parenting styles were not measured in this study and may have contributed to child behaviour problems. Future studies should assess these factors as potential confounders. Maternal mental health at only one time point ( 12 months postpartum) was included in this analysis. Intervening maternal and/or child factors, for example, effects of HIV-related CNS infections or encephalopathy on the developing brain between 12 and 42 months may have contributed to child behavioural outcomes.

More than one administrator was used which may have caused inconsistency in the administration of selfreports. Maternal mental state and child behaviour outcomes were measured using self-reports and not a clinician diagnosis. The mental state of the caregivers may have contributed to biased perceptions of child behaviour being endorsed. Only 70 mother-child dyads participated in the study, and 11 of the 70 dyads were excluded from the regression analysis owing to missing data. The small sample size may have compromised statistical power for the analyses. Lastly, there was no HIV-negative control or comparator group.

Nevertheless, several characteristics of the sample distinguish this study from previous research samples. This is, to our knowledge, the first study investigating the predictive effect of PTSD on child behaviour in vertically transmitted, children infected with HIV. The study followed a longitudinal design and investigated the longterm child outcomes of maternal mental health at a specific point in time. Biological markers (eg, CD4 counts) indicated that the children were relatively healthy at the time of assessment, thus minimising the possibility of poor physical health being a confounding factor. All mother-child dyads had routine check-ups, counselling, HIV information sessions and antiretroviral treatment available to them. The level of intervention and care provided may have contributed positively to maternal mental health and child behaviour outcomes and requires further investigation. Findings of this study highlight the need to screen for and manage maternal PTSD and depression in mothers-child dyads infected with HIV. Identifying the mechanisms by which maternal mental health variables, specifically PTSD, interact and function in relation to child development in vertically transmitted HIV also requires exploration in future larger sample longitudinal studies.

\section{Author affiliations}

${ }^{1}$ Department of Psychiatry, Stellenbosch University, Cape Town, South Africa

${ }^{2}$ School of International Development and Global Studies, University of Ottawa, Ontario, Canada

${ }^{3}$ Department of Paediatrics and Child Health, The Children's Infectious Diseases Clinical Research Unit (KID-CRU), Stellenbosch University, Cape Town, South Africa 
Acknowledgements The authors would like to thank the parents and children taking part in the study and the Children's Infectious Diseases Clinical Research Unit (KID-CRU) personnel. They also thank Lungiswa Rosy Khethelo and Marina Basson for assistance with data collection and Justin Harvey for assistance with the data analysis.

Contributors JN participated in data analysis and interpretation, writing of manuscript. CLM participated in interpretation of analysis and writing of manuscript. BL participated in concept design, oversight of child behaviour data, revision of manuscript, and read and approved the manuscript. MFC participated in revision of manuscript. SS participated in concept design, oversight of data analysis, revision of manuscript, and read and approved the manuscript. Marina Basson and Lungiswa Rosy Khethelo participated in data collection. Dr Justin Harvey participated in data analysis.

Funding Support for this study was provided by the US National Institute of Allergy and Infectious Diseases (NIAID) through the CIPRA network, Grant U19 Al53217; the Departments of Health of the Western Cape and Gauteng, South Africa; and GlaxoSmithKline. Additional support was provided with Federal funds from the National Institute of Allergy and Infectious Diseases, National Institutes of Health, USA, Department of Health and Human Services, under Contract No. HHSN272200800014C. In addition, the study was funded through grants from the Harry Crossley Foundation and the South African Medical Research Council (MRC).

Competing interests None.

Patient consent Obtained

Ethics approval The study under investigation was approved by the Health Research Ethics Committee of Stellenbosch University in Cape Town, South Africa (N05/07/113)

Provenance and peer review Not commissioned; externally peer reviewed.

Data sharing statement No additional data are available.

Open Access This is an Open Access article distributed in accordance with the Creative Commons Attribution Non Commercial (CC BY-NC 3.0) license, which permits others to distribute, remix, adapt, build upon this work noncommercially, and license their derivative works on different terms, provided the original work is properly cited and the use is non-commercial. See: http:// creativecommons.org/licenses/by-nc/3.0/

\section{REFERENCES}

1. Herman AA, Stein DJ, Seedat S, et al. The South African stress and health (SASH) study: 12-month and lifetime prevalence of common mental disorders. S Afr Med J 2009;99:339-44.

2. Atwoli L, Stein DJ, Williams DR, et al. Trauma and posttraumatic stress disorder in South Africa: analysis from the South African Stress and Health Study. BMC Psychiatry 2013;13:182.

3. Tomlinson M, Cooper P, Murray L. The mother-infant relationship and infant attachment in a South African peri-urban settlement. Child Dev 2005;76:1044-54.

4. Joint United Nations Programme on HIV/AIDS (UNAIDS). Report on the global AIDS epidemic, 2010. http://www.unaids.org/globalreport/ global_report.htm (accessed 1 Jul 2013).

5. Bing EG, Burnam MA, Longshore D, et al. Psychiatric disorders and drug use among human immunodeficiency virus-infected adults in the United States. Arch Gen Psychiatry 2001;58:721-8.

6. Ceisla JA, Roberts JE. Meta-analysis of the relationship between HIV infection and risk for depressive disorders. Am J Psychiatry 2001;158:725-30.

7. Olley BO, Seedat S, Stein DJ. Persistence of psychiatric disorders in a cohort of HIV/AIDS patients in South Africa: a 6-month follow-up study. J Psychosom Res 2006;61:479-84.

8. Myer L, Smit J, Le Roux L, et al. Common mental disorders among HIV-infected individuals in South Africa: prevalence, predictors, and validation of brief psychiatric ratings scales. AIDS Patient Care STDs 2008;22:147-58.

9. Murray L, Cooper PJ. The impact of postpartum depression on child development. Int Rev Psychiatry 1996;8:55-63.

10. Carter AS, Garrity-Rokous FE, Chazan-Cohen R, et al. Maternal depression and comorbidity: predicting early parenting, attachment security, and toddler social-emotional problems and competencies. J Am Acad Child Adolesc Psychiatry 2001;40:18-26.
11. Luoma I, Tamminen T, Kaukonen $\mathrm{P}$, et al. Longitudinal study of maternal depressive symptoms and child well-being. J Am Acad Child Adolesc Psychiatry 2001;40:1367-74.

12. Gao W, Paterson J, Abbott M, et al. Maternal mental health and child behaviour problems at 2 years: findings from the pacific islands families study. Aust N Z J Psychiatry 2007;41:885-95.

13. Chronis AM, Baumann BL, Pelham WE, et al. Maternal depression and early positive parenting predict future conduct problems in young children with attention-deficit/hyperactivity disorder. Dev Psychol 2007;43:70-82

14. Chemtob CM, Nomura $\mathrm{Y}$, Rajendran $\mathrm{K}$, et al. Impact of maternal posttraumatic stress disorder and depression following exposure to the September 11 attacks on preschool children's behavior. Child Dev 2010;81:1129-41.

15. Qi CH, Kaiser AP. Behavior problems of preschool children from low-income families: review of the literature. Top Early Child Spec Educ 2003;23:188-216.

16. Kagan J, Snidman N. Early childhood predictors of adult anxiety disorders. Biol Psychiatry 1999;46:1536-41.

17. Williams B, Sanson A, Toumbourou J, et al. Patterns and predictors of teenagers' use of licit and illicit substances in the Australian Temperament Project cohort. Melbourne: University of Melbourne, 2000.

18. Kaminer D, Grimsrud A, Myer L, et al. Risk for post-traumatic stress disorder associated with different forms of interpersonal violence in South Africa. Soc Sci Med 2008;67:1589-95.

19. Olley BO, Zeier MD, Seedat S, et al. Post-traumatic stress disorder among recently diagnosed patients with HIV/AIDS in South Africa. AIDS Care 2005;17:550-7.

20. Dailey DE, Humphreys JC, Rankin SH, et al. An exploration of lifetime trauma exposure in pregnant low-income African American women. Matern Child Health J 2011;15:410-18.

21. Talge NM, Neal C, Glover V, et al. Antenatal maternal stress and long-term effects on child neurodevelopment: how and why? J Child Psychol Psychiatry 2007;48:245-61.

22. Murphy DA, Marelich WD, Armistead L, et al. Anxiety/stress among mothers living with HIV: effects on parenting skills and child outcomes. AIDS Care 2010;22:1449-58.

23. Bayer JK, Hiscock H, Ukoumunne OC, et al. Early childhood aetiology of mental health problems: a longitudinal population-based study. J Child Psychol Psychiatry 2008;49:1166-74.

24. Siantz MLL, Coronado N, Dpvydaitis T. Maternal predictors of behavioural problems among Mexican migrant farmworker children. J Fam Nurs 2010;16:322-43.

25. Barry TD, Dunlap ST, Cotton SJ, et al. The influence of maternal stress and distress on disruptive behaviour problems in boys. J Am Acad Child Adolesc Psychiatry 2005;44:265-73.

26. Rodriquez CM. Association between independent reports of maternal parenting stress and children's internalizing symptomatology. J Child Fam Stud 2011;20:631-9.

27. Chatterji P, Markowitz S. The impact of maternal alcohol and illicit drug use on children's behaviour problems: evidence from the children of the national longitudinal survey of youth. J Health Econ 2001;20:703-31.

28. Mun EY, Fitzgerald HE, Eye AV, et al. Treatment characteristics as predictors of externalising and internalising child behaviour problems in the context of high and low parental psychopathology. Inf Ment Health J 2001;22:393-415.

29. Eiden RD, Edwards EP, Leonard KE. A conceptual model for the development of externalising behaviour problems among kindergarten children of alcoholic families: role of parenting and children's self-regulation. Dev Psychol 2007;43:1187-201.

30. Jones AS. Maternal alcohol abuse/dependence, children's behaviour problems, and home environment: estimates from the national longitudinal survey of youth using propensity score matching. J Stud Alcohol Drugs 2007;266-75.

31. Barry CD. South Africa: alcohol today. Addiction 2005;100:426-9.

32. May PA, Brooke L, Gossage JP, et al. Epidemiology of fetal alcohol syndrome in a South African community in the Western Cape Province. Am J Public Health 2000;90:1905-12.

33. May PA, Gossage JP, Marais A-S, et al. Maternal risk factors for fetal alcohol syndrome and partial fetal alcohol syndrome in South Africa: a third study. Alcohol Clin Exp Res 2008;32:738-53.

34. Parry CDH, Bhana A, Myers B, et al. Alcohol use in South Africa: findings from the South African community epidemiology network on drug use (SACENDU) project. J Stud Alcohol Drugs 2002;63:430-5.

35. Viljoen DL, Gossage JP, Brooke L, et al. Fetal alcohol syndrome epidemiology in a South African community: a second study of a very high prevalence area. J Stud Alcohol Drugs 2005;66:593-604.

36. Molina BSG, Donovan JE, Belenduik KA. Familial loading for alcoholism and offspring behaviour: mediating and moderating influences. Alcohol Clin Exp Res 2010;34:1972-83. 
37. Cotton MF, Violari A, Gibb D, et al. Early ART followed by interruption is safe and is associated with better outcomes that deferred ART in HIV+ infants: final results from the 6-year randomized CHER trial, South Africa. 19th Conference in Retrovirology and Opportunistic Infection 2012. USA: Seattle.

38. World Health Organization (WHO). Laboratory guidelines for enumerating CD4 T Lymphocytes in the context of HIV/AIDS. Regional Office for South-East Asia 2007. http://www.who.int/hiv/ amds/LaboratoryGuideEnumeratingCD4TLymphocytes.pdf (accessed 1 Jul 2013)

39. Mollica R, McDonald L, Massagli M, et al. Measuring trauma, measuring torture, instructions and guidance on the utilization of the Harvard Program in Refugee Trauma's Versions of the Hopkins Symptom Checklist-25 (HSCL-25) and the Harvard Trauma Questionnaire (HTQ). Cambridge, MA: Harvard Program in Refugee Trauma, 2004.

40. Rothon C, Stansfeld SA, Mathews C, et al. Reliability of self report questionnaires for epidemiological investigations of adolescent mental health in Cape Town, South Africa. $J$ Child Adolesc Ment Health 2011;23:119-28.

41. Saunders JB, Aasland OG, Babor TF, et al. Development of the Alcohol Use Disorders Identification Test (AUDIT): WHO Collaborative Project on Early Detection of persons with Harmful Alcohol Consumption-II. Addiction 1993;88:791-804.

42. Bohn MJ, Babor TF, Kranzler HR. The alcohol use identification test (AUDIT): validation of a screening instrument for use in medical settings. J Stud Alcohol 1995;56:423-32.

43. Cherpitel CJ, Clark WB. Ethnic differences in performance of screening instruments for identifying harmful drinking and alcohol dependence in the emergency room. Alcohol Clin Exp Res 1995; 19:628-34.

44. Cherpitel CJ, Borges G. Performance of screening instruments for alcohol problems in the ER: a comparison of Mexican-Americans and Mexicans in Mexico. Am J Drug Alcohol Abuse 2000;26:683-702.

45. Medina-Mora E, Carreno S, de la Fuente JR. Experience with the alcohol use disorders identification test (AUDIT) in Mexico. Recent Dev Alcohol 1998;14:383-96.

46. Seale JP, Seale JD, Alvarado M, et al. Prevalence of problem drinking in a Venezuelan Native American population. Alcohol Alcohol 2002;37:198-204.

47. Leung SF, Arthur D. The alcohol use disorders identification test (AUDIT): validation of an instrument for enhancing nursing practice in Hong Kong. Int J Nurs Stud 2000;37:57-64.

48. Chinyadza E, Moyo IM, Katsumbe TM, et al. Alcohol problems among patients attending five primary health care clinics in Harare city. Cent Afr J Med 1993;39:26-32.

49. Simbayi LC, Kalichman SC, Jooste S, et al. Alcohol use and sexual risks for HIV infection among men and women receiving sexually transmitted infection clinic services in Cape Town, South Africa. J Stud Alcohol Drugs 2004;65:434-42.

50. Shaffer DN, Njeri R, Justice AC, et al. Alcohol abuse among patients with and without HIV infection attending public clinics in western Kenya. East Afr Med J 2004;81:594-8.

51. Boyd JH, Weissman MM, Thompson WD, et al. Screening for depression in a community sample. Understanding the discrepancies between depression and diagnostic scales. Arch Gen Psychiatry 1982;39:1195-2000.

52. Meyers JK, Weissman MM. Use of a self-report symptom scale to detect depression in a community sample. Am J Psychiatry 1980;137:1081-4.

53. Roberts RE, Vernon SW. The Center for Epidemiological Studies Depression Scale: its use in a community sample. Am J Psychiatry $1983 ; 140: 41-6$
54. Ghubash R, Daradkeh TK, Al Naseri KS, et al. The performance of the Center for Epidemiology Study Depression Scale (CES-D) in an Arab female community. Int J Soc Psychiatry 2000;46:241-9.

55. Iwata N, Buka S. Race/ethnicity and depressive symptoms: a cross-cultural/ethnic comparison among university students in East Asia, North and South America. Soc Sci Med 2002;55:2243-52.

56. Munet-Vilaro F, Folkman S, Gregorich S. Depressive symptomatology in three Latino groups. West $J$ Nurs Res 1999;21:209-24.

57. Guarnaccia PJ, Angel R, Worobey JL. The factor structure of the CES-D in the Hispanic Health and Nutrition Examination Survey: the influences of ethnicity, gender and language. Soc Sci Med 1989;29:85-94.

58. Roberts RE, Rhoades HM, Vernon SW. Using the CES-D scale to screen for depression and anxiety: effects of language and ethnic status. Psychiatry Res 1990;31:69-83.

59. Kalichman SC, Rompa D, Cage M. Distinguishing between overlapping somatic symptoms of depression and HIV disease in people living with HIV-AIDS. J Nerv Ment Dis 2000;188:662-70.

60. Simoni JM, Ng MT. Trauma, coping, and depression among women with HIV/AIDS in New York City. AIDS Care 2000;12:567-80.

61. Schuman P, Ohmit SE, Moore J, et al. Human Immunodeficiency Virus Epidemiology Research Study. Perceived need for and use of mental health services by women living with or at risk of human immunodeficiency virus infection. J Am Med Womens Assoc 2001;56:4-8.

62. Eller LS, Mahat G. Psychological factors in Nepali former commercial sex workers with HIV. J Nurs Scholarsh 2003;35:53-60.

63. Sheehan DV. The anxiety disease. New York: Scribner, 1983.

64. Troeman ZCE, Spies G, Cherner M, et al. Impact of childhood trauma on functionality and quality of life in HIV-infected women. Health Qual Life Outcomes 2011;9:84.

65. Achenbach TM, Rescorla LA. Manual for the ASEBA school-age forms and profiles. Burlington: University of Vermont, 2001.

66. Calkins SD, Dedmon SE. Physiological and behavioral regulation in two-year-old children with aggressive/destructive behavior problems. J Abnorm Child Psychol 2000;28:103-18.

67. Gross D, Fogg L, Young M, et al. The equivalence of the child behavior checklist/ 11/2-5 across race/ethnicity, income level, and language. Psychol Assess 2006;18:313-23.

68. Mesman J, Bongers IL, Koot HM. Preschool development pathways to preadolescent internalizing and externalizing problems. J Child Psychol Psychiatry 2001;42:679-89.

69. Cooper PJ, Tomlinson M, Swartz L, et al. Post-partum depression and the mother-infant relationship in a South African peri-urban settlement. Br J Psychiatry 1999;175:554-8.

70. Instone SL. Perceptions of children with HIV infection when not told for so long: implications for diagnosis disclosure. J Pediatr Health Care 2000;14:235-43.

71. Richter LM. Poverty, underdevelopment and infant mental health. J Paediatr Child Health 2003;39:243-8.

72. Hudson JL, Rapee RM. Parent-child interaction and anxiety disorders: an observational study. Behav Res Ther 2001;39:1411-27.

73. Bögels SM, Brechman-Toussaint ML. Family issues in child anxiety: attachment, family functioning, parental rearing and beliefs. Clin Psychol Rev 2006;26:834-56.

74. O'Connor TG, Heron J, Golding J. et al. Report from the Avon longitudinal study of parents and children. $\mathrm{Br} J$ Psychiatry 2002;180:502-8.

75. Katwan E, Adnams C, London L. Childhood behavioural and developmental disorders associated with maternal alcohol consumption in Cape Town, South Africa. S Afr Med J 2011;101:724-7. 